\title{
Mortality in patients with dementia after ischemic stroke
}

\author{
David W. Desmond, PhD; Joan T. Moroney, MD, MRCPI; Mary Sano, PhD; and Yaakov Stern, PhD
}

\begin{abstract}
Objective: Although dementia is typically considered to be a consequence of a variety of neurologic diseases, it can also serve as a risk factor for other adverse outcomes. The authors investigated dementia as a predictor of long-term survival among patients with ischemic stroke. Methods: Neurologic, neuropsychological, and functional assessments were administered to 453 patients (mean age $\pm \mathrm{SD}, 72.0 \pm 8.3$ years) 3 months after ischemic stroke. The authors diagnosed dementia in 119 (26.3\%) of the patients using modified Diagnostic and Statistical Manual of Mental Disorders, Revised 3rd Edition, criteria requiring deficits in memory and two or more additional cognitive domains as well as functional impairment. Dementia as a predictor of long-term survival during up to 10 years of follow-up was then investigated. Results: The mortality rate was 15.90 deaths per 100 person-years among patients with dementia and 5.37 deaths per 100 person-years among nondemented patients. A Cox proportional hazards analysis found that the relative risk (RR) of death was increased in association with dementia $(\mathrm{RR}=2.4 ; 95 \% \mathrm{CI}=1.6$ to 3.4), adjusting for the following: a major hemispheral stroke syndrome $(\mathrm{RR}=1.4)$; a middle cerebral artery territory index stroke $(\mathrm{RR}=1.7)$; a Stroke Severity Scale score of $\geq 4$, representing more severe stroke $(R R=1.8)$; atrial fibrillation $(R R=1.8)$; congestive heart failure $(R R=$ $2.2)$; recurrent stroke occurring during follow-up $(\mathrm{RR}=3.9)$; and demographic variables. The risk of death increased in association with the severity of dementia, but it did not differ by dementia subtype. Conclusions: Dementia is a significant independent risk factor for reduced survival after ischemic stroke, adjusting for other recognized predictors of mortality. The authors hypothesize that patients with dementia are at an elevated risk of mortality because of their increased burden of cerebrovascular disease, a tendency toward undertreatment for stroke prophylaxis among clinicians, or patient noncompliance with treatment regimens.
\end{abstract}

NEUROLOGY 2002;59:537-543

Stroke is the leading cause of death among neurologic diseases and the third leading cause of death among all medical conditions. ${ }^{1}$ Factors that increase the risk of death soon after stroke include the size, location, and clinical severity of the infarction, whereas physical disability, comorbid illnesses such as cardiac disease, and older age are associated with reduced long-term survival. ${ }^{2-5}$ In addition, patients with stroke are at an elevated risk of recurrent stroke, which can also increase their risk for death. ${ }^{6}$

Dementia is typically considered to be a consequence of a variety of neurologic diseases, but it can also serve as a risk factor for other adverse outcomes. ${ }^{7}$ Many studies have investigated dementia as a predictor of long-term survival, ${ }^{8-15}$ and a number of investigations have compared the risk associated with different dementia subtypes, including vascular dementia. ${ }^{8,10-21}$ Despite the frequency with which dementia is diagnosed after ischemic stroke, ${ }^{22-24}$ however, most stroke outcome studies have failed to examine it as a potential predictor of long-term survival.

The current study was conducted to investigate dementia as a determinant of long-term survival among patients with ischemic stroke. Since our pre- vious report on this topic, ${ }^{25}$ we have recruited, examined, and followed a second large cohort of patients with ischemic stroke and extended the follow-up of our first cohort of patients in an effort to answer four specific questions: 1) Does dementia increase the risk of mortality among patients with ischemic stroke after adjusting for other relevant risk factors? 2) Do patients with dementia primarily due to the effects of cerebrovascular disease differ from patients with $\mathrm{AD}$ with concomitant stroke in regard to their risk of mortality? 3) Is an increasing severity of dementia associated with an increasing risk of mortality? 4) Can stroke patients with and without dementia be distinguished on the basis of their immediate or underlying causes of death?

Methods. Subjects. As part of a longitudinal study of stroke and dementia, ${ }^{23}$ we recruited 585 subjects among patients consecutively admitted to Columbia-Presbyterian Medical Center for ischemic stroke. We recruited 297 of those patients from 1988 to 1990 and the remaining 288 patients from 1994 to 1997, those two recruitment phases corresponding to two funding cycles. Eligibility requirements included an age of 60 years or older and a diagnosis of ischemic stroke within the previous 30 days confirmed

From the Departments of Neurology and Pathology (Dr. Desmond), SUNY Downstate Medical Center, Brooklyn, NY; the Department of Clinical Neurosciences (Dr. Moroney), Royal College of Surgeons in Ireland, Beaumont Hospital, Dublin; and the Departments of Neurology and Psychiatry and the Gertrude H. Sergievsky Center (Drs. Stern and Sano), Columbia University, College of Physicians and Surgeons, New York, NY.

Supported by grants R01-NS26179, P01-AG07232, K07-AG00959, and K08-NS02051 from the NIH.

Received December 28, 2001. Accepted in final form April 25, 2002.

Address correspondence and reprint requests to Dr. Desmond, SUNY Downstate Medical Center, 450 Clarkson Avenue, Box 25, Brooklyn, NY 11203; e-mail: dwdesmond@usa.net 
by brain imaging (relevant infarct or normal). Patients were excluded when certain clinical features precluded a reliable assessment of cognitive function, including a Boston Diagnostic Aphasia Examination ${ }^{26}$ severity rating of $<3$ (lower scores represent greater severities), persistent impairment of consciousness, or a primary language other than English or Spanish. Additional exclusion criteria included the presence of a concomitant neurologic disorder potentially affecting cognitive function (e.g., PD) or a severe comorbid medical illness (e.g., terminal cancer) that would preclude follow-up throughout the course of this longitudinal study. Based on neuropsychological and functional assessments performed 3 months after stroke and modified criteria from the Diagnostic and Statistical Manual of Mental Disorders, Revised 3rd Edition, ${ }^{27}$ all of which are described in detail below, we diagnosed dementia in $119(26.3 \%)$ of the 453 patients with ischemic stroke who were available for examination. ${ }^{23}$ Those 453 patients (mean age $\pm \mathrm{SD}=72.0 \pm 8.3$ years) constitute the cohort on which the current study is based.

The Institutional Review Board of Columbia-Presbyterian Medical Center approved the study, and all subjects provided informed consent.

Assessment procedures and follow-up. Seven to 10 days after stroke onset, neurologists specializing in stroke administered a structured neurologic examination and documented any history of stroke, TIA, or exposure to risk factors for cerebrovascular disease based on review of medical records and a structured interview administered to all patients and knowledgeable informants. A comprehensive medical history was also recorded. Based on the review of clinical features and brain imaging performed immediately after stroke, patients were classified by infarct location and stroke syndrome using a modification of the methods of the Stroke Data Bank. ${ }^{28}$

We performed our baseline comprehensive assessment of all patients 3 months after stroke. We then examined all patients annually based on the date of stroke onset using the same assessment protocol. During the baseline assessment and all annual examinations, all patients were administered a comprehensive battery of neuropsychological tests developed for use in epidemiologic studies of dementia, ${ }^{29}$ which is described in detail in another publication, ${ }^{23}$ with testing performed in either English or Spanish based on the language spoken in the subject's home; the MiniMental State Examination (MMSE), ${ }^{30}$ which was not part of our dementia diagnosis paradigm; the Barthel Index, ${ }^{31}$ which taps the physical aspects of activities of daily living; and the Structured Interview Guide for the Hamilton Depression Rating Scale, ${ }^{32}$ with depression defined as a Structured Interview Guide for the Hamilton Depression Rating Scale total score of $>11$ and the acknowledgment of depressed mood. Knowledgeable informants were administered the Blessed Functional Activity Scale, ${ }^{33}$ which taps the cognitive aspects of activities of daily living. Neurologists specializing in stroke administered a structured neurologic examination and documented any recurrent strokes and intercurrent illnesses that may have occurred. Patients with stroke were also rated on the Stroke Data Bank Stroke Severity Scale. ${ }^{28}$

To maximize follow-up rates, we made visits to subjects' homes or health care facilities if they were unable or un- willing to be examined in our clinic, and we did not consider subjects to be "refusals" for a particular interval until at least four attempts had been made to contact and examine them. When in-person examinations were not possible, we obtained information by telephone to ascertain vital status and the occurrence of major clinical events. For patients who died, the exact dates of death were recorded or they were approximated when necessary, and the determination of the immediate and any underlying causes of death was based on all available information, including death certificates and records of the terminal hospitalization.

Dementia diagnosis. Dementia was diagnosed based on criteria modified from the Diagnostic and Statistical Manual of Mental Disorders, Revised 3rd Edition, and consistent with criteria later proposed by the International Workshop of the National Institute of Neurological Disorders and Stroke-Association Internationale pour la Recherche et l'Enseignement en Neurosciences. ${ }^{34} \mathrm{We}$ required deficits in memory and two or more additional cognitive domains as determined in the neuropsychological evaluation as well as functional impairment not solely related to physical disability documented with the Blessed Functional Activity Scale. When patients were aphasic, we required that they exhibit evidence of nonverbal memory impairment. We defined impairment within any cognitive domain as any neuropsychological test score within that domain falling below a predetermined cutoff that was selected in a pilot study. In previous work, we noted that a diagnosis of dementia based on this paradigm had the greatest validity as a predictor of death among stroke patients, while diagnoses based on less stringent operationalized criteria, the MMSE, and the examining neurologist's clinical judgment were only weakly related. ${ }^{7}$

The primary clinical subtypes of dementia were defined based on the temporal association between stroke and the onset of the dementia syndrome as well as correlations between clinical and neuropsychological features. Essentially, cerebrovascular disease was considered to be the primary etiology when stroke resulted in the new onset of dementia, while $\mathrm{AD}$ with stroke was diagnosed when functional impairment preceded the index stroke based on the best historical information.

Statistical analyses. We calculated survival time from the date of the baseline examination. Failure time was considered to be the date of death, and reasons for censoring included patient loss to follow-up or reaching the end of formal study follow-up on May 31, 1999. When patients were lost to follow-up, the date of censoring was assigned to the midpoint of the corresponding follow-up interval. The crude incidence rate of mortality, stratified by dementia status, was calculated using life-table methods.

We performed log-rank tests to investigate dementia status; the location, syndrome, and severity of the presenting stroke; vascular risk factors; and demographic variables as potential predictors of death. We also performed an unadjusted Cox proportional hazards analysis to investigate the risk associated with first recurrent stroke, which was entered as a time-dependent covariate. We then performed a multivariate Cox proportional hazards analysis to determine whether any of the variables that were found to be related to death in those univariate analyses $(p<$ 0.10 ) would be independently related to death. 


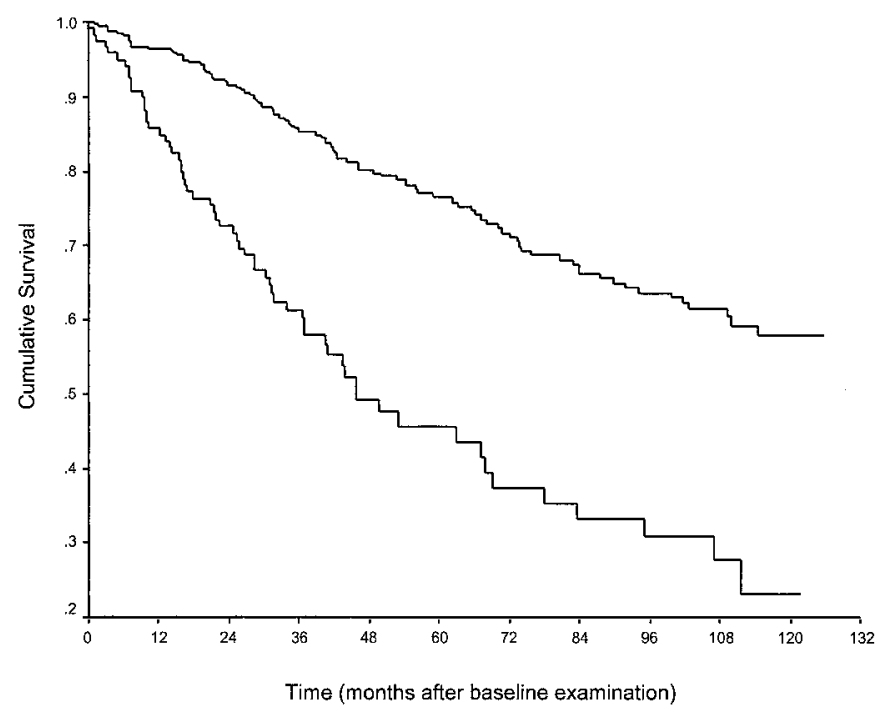

Figure. Kaplan-Meier analysis showing the cumulative proportion of subjects surviving stratified by dementia status during follow-up of up to $\approx 120$ months (patients with dementia are represented by the lower line and patients without dementia are represented by the upper line).

Results. Frequency of death by dementia status. Median follow-up was 31.5 months (range $=0.2$ to 121.8 months) among patients with dementia and 48.8 months (range $=1.0$ to 125.8 months) among nondemented patients. Thirty patients $(6.6 \%$ of the cohort) were lost to follow-up. Overall, 153 deaths (33.8\% of the cohort) occurred. Of 119 patients with dementia, 63 (52.9\%) died during 396.1 person-years of follow-up, yielding a crude incidence rate of 15.90 deaths per 100 person-years. Of 334 nondemented patients, $90(27.0 \%)$ died during $1,675.1$ person-years of follow-up, yielding a crude incidence rate of 5.37 deaths per 100 person-years. As shown in the figure, a log-rank test determined that the survival curves of the groups of patients with and without dementia were different $(p<0.0001)$.

Predictors of death. Demographic variables and vascular risk factors stratified by death are shown in table 1 . Index stroke characteristics and recurrent stroke stratified by death are shown in table 2. Log-rank tests determined that age, atrial fibrillation, congestive heart failure, stroke syndrome, stroke location, vascular territory, stroke mechanism, stroke severity, and dementia were significantly associated with death. An unadjusted Cox proportional hazards analysis found that recurrent stroke, entered as a time-dependent covariate, was also significantly related to death. Given that the stroke syndrome, vascular territory, and stroke mechanism variables each contained numerous response options, we recoded them into dichotomous variables and found that a major hemispheral stroke syndrome, middle cerebral artery territory infarctions, and embolic infarctions were associated with an increased risk of death. Regarding the primary dementia subtypes, the risk of death did not differ significantly between patients with cerebrovascular disease as the primary basis for their dementia syndrome $(51.5 \%$ of whom had died or 14.37 deaths per 100 person-years) and patients with $\mathrm{AD}$ with concomitant stroke $(53.3 \%$ of whom had died or 18.51 deaths per 100 person-years) by a log-rank test.
Table 1 Demographic variables and vascular risk factors by death in a study of mortality in patients with dementia after ischemic stroke

\begin{tabular}{|c|c|c|c|}
\hline \multirow[b]{2}{*}{ Variable } & \multicolumn{2}{|c|}{ Death } & \multirow[b]{2}{*}{$p$ Value } \\
\hline & $\begin{array}{c}\text { Yes, } \\
\mathrm{n}=153\end{array}$ & $\begin{array}{c}\text { No } \\
\mathrm{n}=300\end{array}$ & \\
\hline \multicolumn{4}{|l|}{ Age, y } \\
\hline$\geq 80$ & $42(27.5)$ & $41(13.7)$ & $<0.001$ \\
\hline $70-79$ & $60(39.2)$ & $103(34.3)$ & \\
\hline $60-69$ & $51(33.3)$ & $156(52.0)$ & \\
\hline Education ( $\leq 8 \mathrm{y})$ & $52(34.0)$ & $113(37.7)$ & 0.883 \\
\hline Race/ethnicity (nonwhite) & $105(68.6)$ & $224(74.7)$ & 0.666 \\
\hline Sex (female) & $86(56.2)$ & $152(50.7)$ & 0.305 \\
\hline Hypertension & $110(72.4)$ & $221(73.7)$ & 0.947 \\
\hline Diabetes mellitus & $56(36.6)$ & $100(33.3)$ & 0.256 \\
\hline Myocardial infarction & $26(17.1)$ & $47(15.8)$ & 0.642 \\
\hline Angina & $30(20.3)$ & $68(22.7)$ & 0.753 \\
\hline Atrial fibrillation & $35(23.0)$ & $23(7.7)$ & $<0.001$ \\
\hline Congestive heart failure & $27(17.9)$ & $18(6.0)$ & $<0.001$ \\
\hline Consistent cigarette use & $85(56.7)$ & $177(59.4)$ & 0.531 \\
\hline Consistent alcohol use & $73(49.0)$ & $149(50.0)$ & 0.997 \\
\hline Prior stroke & $40(26.5)$ & $69(23.0)$ & 0.283 \\
\hline Prior transient ischemic attack & $20(13.2)$ & $53(18.0)$ & 0.111 \\
\hline
\end{tabular}

Figures are frequencies and within-group percentages. Significance levels are based on log-rank tests. "Consistent cigarette use" was defined as smoking at least one cigarette per day for at least 1 year, and "consistent alcohol use" was defined as consuming at least one serving of beer, wine, or hard liquor per week for at least 6 months.

An unadjusted Cox proportional hazards analysis determined that dementia was associated with a significantly increased risk of death (relative risk $[R R]=2.98 ; 95 \%$ $\mathrm{CI}=2.15$ to 4.12 ). Adding demographic variables to that model, we found that dementia remained associated with an increased risk of death $(\mathrm{RR}=2.70 ; 95 \% \mathrm{CI}=1.90$ to 3.84), adjusting for the following: age of 80 years or older $(\mathrm{RR}=1.94 ; 95 \% \mathrm{CI}=1.24$ to 3.02$)$ and age of 70 to 79 years $(\mathrm{RR}=1.43 ; 95 \% \mathrm{CI}=0.97$ to 2.11$)$ vs age of 60 to 69 years, education of $\leq 8$ years $(\mathrm{RR}=0.95 ; 95 \% \mathrm{CI}=0.67$ to 1.35), nonwhite race/ethnicity $(\mathrm{RR}=0.81 ; 95 \% \mathrm{CI}=0.56$ to 1.18$)$, and female sex $(\mathrm{RR}=1.10 ; 95 \% \mathrm{CI}=0.78$ to 1.53). Finally, in our primary Cox proportional hazards model, dementia remained associated with an increased risk of death $(\mathrm{RR}=2.37 ; 95 \% \mathrm{CI}=1.64$ to 3.43$)$, adjusting for the following: a major hemispheral stroke syndrome $(\mathrm{RR}=1.38 ; 95 \% \mathrm{CI}=0.94$ to 2.04$)$; a middle cerebral artery territory infarct vs infarcts in all other vascular territories $(\mathrm{RR}=1.72 ; 95 \% \mathrm{CI}=1.21$ to 2.42$)$; a Stroke Severity Scale score of $\geq 4$, representing more severe stroke $(\mathrm{RR}=1.79 ; 95 \% \mathrm{CI}=1.25$ to 2.57$)$; atrial fibrillation $(\mathrm{RR}=1.80 ; 95 \% \mathrm{CI}=1.18$ to 2.75$)$; congestive heart failure $(\mathrm{RR}=2.18 ; 95 \% \mathrm{CI}=1.41$ to 3.38$)$; recurrent stroke entered as a time-dependent covariate $(\mathrm{RR}=3.91$; $95 \% \mathrm{CI}=2.70$ to 5.65$)$; age of 80 years or older $(\mathrm{RR}=1.60$; $95 \% \mathrm{CI}=1.00$ to 2.54$)$ and age of 70 to 79 years $(\mathrm{RR}=$ $1.20 ; 95 \% \mathrm{CI}=0.80$ to 1.80$)$ vs age of 60 to 69 years; 
Table 2 Index stroke characteristics and recurrent stroke by death in a study of mortality in patients with dementia after ischemic stroke

\begin{tabular}{|c|c|c|c|}
\hline \multirow[b]{2}{*}{ Variable } & \multicolumn{2}{|c|}{ Death } & \multirow[b]{2}{*}{$p$ Value } \\
\hline & $\begin{array}{c}\text { Yes, } \\
\mathrm{n}=153\end{array}$ & $\begin{array}{c}\text { No, } \\
\mathrm{n}=300\end{array}$ & \\
\hline \multicolumn{4}{|l|}{ Stroke syndrome } \\
\hline Major dominant hemispheral & $15(9.8)$ & $19(6.3)$ & $<0.001$ \\
\hline $\begin{array}{l}\text { Major nondominant } \\
\text { hemispheral }\end{array}$ & $23(15.0)$ & $19(6.3)$ & \\
\hline Minor dominant hemispheral & $22(14.4)$ & $37(12.3)$ & \\
\hline $\begin{array}{l}\text { Minor nondominant } \\
\text { hemispheral }\end{array}$ & $25(16.3)$ & $29(9.7)$ & \\
\hline Lacunar/deep hemispheral & $44(28.8)$ & $131(43.7)$ & \\
\hline Brainstem/cerebellar & $24(15.7)$ & $65(21.7)$ & \\
\hline \multicolumn{4}{|l|}{ Stroke location } \\
\hline Left hemisphere & $55(33.9)$ & $95(31.8)$ & 0.002 \\
\hline Right hemisphere & $70(45.8)$ & $100(33.4)$ & \\
\hline Brainstem/cerebellum & $28(18.3)$ & $104(34.8)$ & \\
\hline \multicolumn{4}{|l|}{ Vascular territory } \\
\hline ICA & $2(1.3)$ & $17(5.7)$ & $<0.001$ \\
\hline ACA & $6(3.9)$ & $10(3.3)$ & \\
\hline $\mathrm{MCA}$ & $101(66.0)$ & $122(40.7)$ & \\
\hline PCA & $15(9.8)$ & $49(16.3)$ & \\
\hline Vertebrobasilar & $29(19.0)$ & $102(34.0)$ & \\
\hline \multicolumn{4}{|l|}{ Stroke mechanism } \\
\hline Large artery atherosclerosis & $30(19.6)$ & $58(19.3)$ & 0.001 \\
\hline Cardiac embolism & $41(26.8)$ & $45(15.0)$ & \\
\hline Lacunar & $42(27.5)$ & $128(42.7)$ & \\
\hline Unknown/other cause & $40(26.1)$ & $69(23.0)$ & \\
\hline Stroke Severity Scale score of $\geq 4$ & $93(61.6)$ & $112(39.6)$ & $<0.001$ \\
\hline Depression & $17(12.1)$ & $23(8.3)$ & 0.106 \\
\hline Dementia & $63(41.2)$ & $56(18.7)$ & $<0.001$ \\
\hline Recurrent stroke & $44(28.8)$ & $52(17.3)$ & $<0.001$ \\
\hline
\end{tabular}

Figures are frequencies and within-group percentages. Significance levels are based on log-rank tests for all variables except recurrent stroke, which was entered into an unadjusted Cox proportional hazards analysis as a time-dependent covariate.

$\mathrm{ICA}=$ internal carotid artery; $\mathrm{ACA}=$ anterior cerebral artery; $\mathrm{MCA}=$ middle cerebral artery $\mathrm{PCA}=$ posterior cerebral artery

education of $\leq 8$ years $(\mathrm{RR}=0.91 ; 95 \% \mathrm{CI}=0.64$ to 1.31$)$; nonwhite race/ethnicity $(\mathrm{RR}=0.83 ; 95 \% \mathrm{CI}=0.56$ to $1.22)$; and female sex ( $R R=0.84 ; 95 \% \mathrm{CI}=0.59$ to 1.18$)$. No significant interactions were obtained between dementia and other relevant variables in this model.

We also examined the severity of dementia based on the MMSE score received 3 months after stroke as a predictor of survival among the 119 patients with dementia. We found that $7(77.8 \%)$ of 9 patients with MMSE scores of 0 to $9,26(65 \%)$ of 40 patients with MMSE scores of 10 to 19 , and $27(40.9 \%)$ of 66 patients with MMSE scores of $\geq 20$ had died. A baseline MMSE score was unavailable for four patients with dementia. In an unadjusted Cox proportional hazards analysis, the RR associated with the severity of dementia, as represented by the baseline MMSE score, were $6.22(95 \% \mathrm{CI}=2.57$ to 15.07$)$ for an MMSE score of 0 to 9 and 2.90 ( $95 \% \mathrm{CI}=1.65$ to 5.09) for an MMSE score of 10 to 19 vs an MMSE score of $\geq 20$. The results of that analysis were essentially unchanged when demographic variables and recurrent stroke were entered as covariates.

Causes of death. A specific immediate cause or mode of death could be determined for 110 (71.9\%) of the 153 patients who died, typically those who died at our medical center. Cardiopulmonary arrest was recorded as the mode of death in $103(93.6 \%)$ of those 110 patients. One or more specific underlying causes of death were identified for 84 $(54.9 \%)$ of the 153 patients who died. Among patients for whom one or more underlying causes of death were specifically identified or excluded, those causes included infections such as pneumonia (26.1\% of demented patients and $20.7 \%$ of nondemented patients who died; $p=0.516$ by $\chi^{2}$ testing), cerebrovascular disease $(29.8 \%$ of demented patients and $23.0 \%$ of nondemented patients who died; $p=$ $0.422)$, cardiac disease $(18.2 \%$ of demented patients and $20.7 \%$ of nondemented patients who died; $p=0.752$ ), and malignancies $(5.3 \%$ of demented patients and $19.0 \%$ of nondemented patients who died; $p=0.070$ ).

Discussion. Our results suggest that patients with dementia after ischemic stroke are at a two- to threefold increased risk of death relative to nondemented patients, adjusting for the significant effects of a variety of clinical predictors recognized in previous studies, ${ }^{2-5}$ including a major hemispheral stroke syndrome, a middle cerebral artery territory index stroke, greater stroke severity, atrial fibrillation, congestive heart failure, and recurrent stroke occurring during follow-up, as well as demographic factors. Consistent with the concept of a "dose response," our study, like prior studies, ${ }^{9,11,35,36}$ also found that increasing severities of dementia were associated with an increasing risk of death. It is important to note that clinically significant stroke can result in early death, but we performed our first dementia assessments 3 months after stroke. Thus, some patients who might have met dementia criteria if we had assessed them sooner after stroke died before that 3-month assessment, perhaps resulting in an underestimation of the true magnitude of the association between dementia and death.

We propose three mechanisms that may underlie the elevated risk of death among patients with dementia after stroke. First, patients with dementia after stroke have an increased burden of cerebrovascular disease that may in turn increase their risk of death. Although certain variables representing that burden were included as covariates in our primary Cox proportional hazards model, such as a major hemispheral stroke syndrome, there may have been other variables that were not included, such as the cumulative volume or number of infarctions, and dementia may have served as a surrogate for those variables. Second, we and other investigators have previously reported that patients with dementia tend to be treated less aggressively for stroke prophylax- 
is $^{37,38}$ as well as other medical conditions. ${ }^{39}$ Undertreatment for stroke prophylaxis is likely to increase the risk of recurrent stroke, which was an additional significant predictor of death in our final model. Third, patients with dementia by definition have impaired cognitive function, and for that reason they may be less compliant with those treatment regimens that are actually prescribed.

To our knowledge, every published study that has focused on the association between dementia status and mortality has found that patients with dementia are at an increased risk for death relative to nondemented patients. ${ }^{8-15}$ Most studies have shown that patients with vascular dementia have shorter ${ }^{8,10-17,19,21}$ or comparable ${ }^{18,20}$ survival relative to patients with $\mathrm{AD}$, but little attention has been given to long-term outcome among patients with dementia after stroke.

In a recent population-based investigation ${ }^{15}$ focusing on "vascular cognitive impairment" (VCI), ${ }^{40}$ 5 -year survival was examined in 149 patients with VCI not meeting criteria for dementia, 208 patients with VCI meeting criteria for dementia or vascular dementia, and 136 patients with $\mathrm{AD}$ with a vascular component. Overall, patients with VCI had significantly shorter survival than a sample of control subjects $(\mathrm{RR}=1.8 ; 95 \% \mathrm{CI}=1.5$ to 2.3$)$ and survival comparable with that of a separate sample of 747 patients with probable $\mathrm{AD}$. The survival of control subjects, patients with VCI not meeting criteria for dementia, patients with $\mathrm{AD}$ with a vascular component, and patients with vascular dementia declined in the expected direction, but that finding was not significant. In a longitudinal study of 115 patients with multi-infarct dementia and 218 patients with $\mathrm{AD}, 6$-year survival was $21.1 \%$ for patients with $\mathrm{AD}$ vs an expected survival of $48.5 \%$ and $11.9 \%$ for patients with multi-infarct dementia vs an expected survival of $45.2 \%,{ }^{17}$ while 14 -year survival was $2.4 \%$ for patients with $\mathrm{AD}$ vs an expected survival of $16.6 \%$ and $1.7 \%$ for patients with multi-infarct dementia vs an expected survival of $13.3 \% .{ }^{19}$ Finally, 5 -year survival was examined in 53 patients with multi-infarct dementia, 127 patients with $\mathrm{AD}$, and a control sample in a study that was performed in Shanghai, China. ${ }^{10} \mathrm{RR}$ for mortality were $7.2(95 \%$ $\mathrm{CI}=3.6$ to 14.4$)$ for patients with multi-infarct dementia and 5.4 (95\% CI $=2.0$ to 14.6$)$ for patients with $\mathrm{AD}$ among subjects aged 65 to 74 years and 3.5 (95\% CI $=2.4$ to 5.1) for patients with multi-infarct dementia and 2.8 (95\% CI $=2.1$ to 3.6$)$ for patients with $\mathrm{AD}$ among subjects aged 75 years or older. In contrast to the findings of many prior studies, we did not note a significant difference in survival between the clinically diagnosed subtypes of dementia resulting primarily from cerebrovascular disease and $\mathrm{AD}$ with concomitant stroke in our study. In part, this may have been due to the fact that all patients in both groups had experienced at least a minor stroke, perhaps increasing the apparent strength of $\mathrm{AD}$ as a risk factor when present.

Although we did not note any significant differ- ences between the frequencies of the underlying causes of death between demented and nondemented patients, inspection of those frequencies suggested that infections such as pneumonia and significant cerebrovascular disease, including recurrent stroke, were more common underlying causes of death among patients with dementia, while malignancies and specific forms of cardiac disease were more common among nondemented patients. Numerous previous studies have identified pneumonia as an important cause of death among patients with dementia, ${ }^{17,41-43}$ particularly in a setting of stroke, ${ }^{44}$ and recurrent cerebrovascular events have been reported to be important in patients with multi-infarct or vascular dementia. ${ }^{14,17}$ It has also been suggested that malignancies are less common among patients with dementia. ${ }^{17,41,42}$ In general, patients with $\mathrm{AD}$ tend to have fewer comorbid medical conditions than patients with other dementia subtypes, perhaps accounting in part for their typically longer survival. ${ }^{21}$

Our study has certain limitations. First, we did not have neuropathologic confirmation of the dementia subtype in our patients. Although we did not recognize a significant difference in survival between patients with the clinically diagnosed subtypes of dementia resulting primarily from the effects of cerebrovascular disease and $\mathrm{AD}$ with concomitant stroke, that finding might have been modified if those dementia subtypes had been determined neuropathologically. In addition, routine autopsies would have provided us with a better understanding of the relative frequencies of different causes of death by dementia status and dementia subtype. Second, although it was our intention to focus on the clinical determinants of death after stroke, certain quantitative brain imaging measures (e.g., the cumulative volume of infarction) might have been relevant to mortality. Third, we did not examine the contribution of genetic factors, such as the $A P O E-\epsilon 4$ allele, to survival, and these warrant further study.

The findings of this investigation, when considered in combination with the results of certain of our previous studies, allow us to attempt to characterize the complex natural history of dementia after stroke in perhaps its most stereotypic form. Following a period of indeterminate length in which cerebrovascular disease and any associated cognitive deficits are absent, patients may develop mild cognitive deficits in association with certain vascular risk factors, such as diabetes mellitus. ${ }^{45}$ Next, those vascular risk factors may result in a clinically evident or "silent" first cerebral infarction, exacerbating those baseline cognitive deficits. ${ }^{46}$ Following that first cerebral infarction, one or more clinically evident or "silent" recurrent strokes, as well as certain comorbid medical conditions, such as those that might result in cerebral hypoxia or ischemia, may then cause further cognitive decline and dementia. ${ }^{47,48}$ Finally, dementia may then serve as a risk factor for additional recurrent strokes ${ }^{49}$ further cognitive decline, and death. It is important to note that certain of the 
components of this dynamic process may serve as both a risk factor and an adverse outcome, with dementia, for example, serving as both a consequence of and a risk factor for recurrent stroke. Although neurologists can gather information relevant to a diagnosis of dementia by performing structured mental status examinations and obtaining detailed functional histories, comprehensive neuropsychological testing remains the best method for the identification of patients with cognitive impairment that places them at elevated risk for adverse outcomes such as early death. ${ }^{7}$

\section{Acknowledgment}

The authors thank the staff of the Stroke and Aging Research Project for their assistance with data collection.

\section{References}

1. Murphy SL. Deaths: final data for 1998. National vital statistics reports. Vol 48. No 11. Hyattsville, MD: National Center for Health Statistics, 2000.

2. Chambers BR, Norris JW, Shurvell BL, Hachinski VC. Prognosis of acute stroke. Neurology 1987;37:221-225

3. Broderick JP, Phillips SJ, O'Fallon WM, Frye RL, Whisnant JP. Relationship of cardiac disease to stroke occurrence, recurrence, and mortality. Stroke 1992;23:1250-1256.

4. Petty GW, Brown RD, Whisnant JP, Sicks JD, O'Fallon WM, Wiebers DO. Survival and recurrence after first cerebral infarction. A population-based study in Rochester, Minnesota, 1975 through 1989. Neurology 1998;50:208-216.

5. Baptista MV, van Melle G, Bogousslavsky J. Prediction of in-hospital mortality after first-ever stroke: the Lausanne Stroke Registry. J Neurol Sci 1999;166:107-114.

6. Moroney JT, Bagiella E, Paik MC, Sacco RL, Desmond DW. Risk factors for early recurrence after ischemic stroke: the role of stroke syndrome and subtype. Stroke 1998;29:2118-2124.

7. Desmond DW, Moroney JT, Bagiella E, Sano M, Stern Y. Dementia as a predictor of adverse outcomes following stroke: an evaluation of diagnostic methods. Stroke 1998;29:69-74.

8. Martin DC, Miller JK, Kapoor W, Arena VC, Boller F. A controlled study of survival with dementia. Arch Neurol 1987; 44:1122-1126.

9. Evans DA, Smith LA, Scherr PA, Albert MS, Funkenstein $\mathrm{HH}$, Hebert LE. Risk of death from Alzheimer's disease in a community population of older persons. Am J Epidemiol 1991; 134:403-412.

10. Katzman R, Hill LR, Yu ESH, et al. The malignancy of dementia. Predictors of mortality in clinically diagnosed dementia in a population survey of Shanghai, China. Arch Neurol 1994;51:1220-1225.

11. Aevarsson O, Svanborg A, Skoog I. Seven-year survival rate after age 85 years. Relation to Alzheimer disease and vascular dementia. Arch Neurol 1998;55:1226-1232.

12. Agüero-Torres H, Fratiglioni L, Guo Z, Viitanen M, Winblad B. Mortality from dementia in advanced age: a 5-year follow-up study of incident dementia cases. J Clin Epidemiol 1999;52:737-743.

13. Baldereschi M, Di Carlo A, Maggi S, et al. Dementia is a major predictor of death among the Italian elderly. Neurology 1999;52:709-713.

14. Østbye T, Hill G, Steenhuis R. Mortality in elderly Canadians with and without dementia. A 5-year follow-up. Neurology 1999;53:521-526.

15. Rockwood K, Wentzel C, Hachinski V, Hogan DB, MacKnight $\mathrm{C}, \mathrm{McD}$ owell I. Prevalence and outcomes of vascular cognitive impairment. Neurology 2000;54:447-451.

16. Barclay LL, Zemcov A, Blass JP, Sansone J. Survival in Alzheimer's disease and vascular dementias. Neurology 1985;35: $834-840$.

17. Mölsä PK, Marttila RJ, Rinne UK. Survival and cause of death in Alzheimer's disease and multi-infarct dementia. Acta Neurol Scand 1986;74:103-107.

18. Hier DB, Warach JD, Gorelick PB, Thomas J. Predictors of survival in clinically diagnosed Alzheimer's disease and multiinfarct dementia. Arch Neurol 1989;46:1213-1216.
19. Mölsä PK, Marttila RJ, Rinne UK. Long-term survival and predictors of mortality in Alzheimer's disease and multiinfarct dementia. Acta Neurol Scand 1995;91:159-164.

20. Agüero-Torres H, Fratiglioni L, Guo Z, Viitanen M, Winblad B. Prognostic factors in very old demented adults: a sevenyear follow-up from a population-based survey in Stockholm. J Am Geriatr Soc 1998;46:444-452.

21. Landi F, Gambassi G, Lapane KL, Sgadari A, Mor V, Bernabei R. Impact of the type and severity of dementia on hospitalization and survival of the elderly. Dement Geriatr Cogn Disord 1999;10:121-129.

22. Pohjasvaara T, Erkinjuntti T, Vataja R, Kaste M. Dementia three months after stroke: baseline frequency and effect of different definitions of dementia in the Helsinki Stroke Aging Memory Study (SAM) cohort. Stroke 1997;28:785-792.

23. Desmond DW, Moroney JT, Paik MC, et al. Frequency and clinical determinants of dementia after ischemic stroke. Neurology 2000;54:1124-1131.

24. Barba R, Martínez-Espinosa S, Rodríguez-García E, Pondal M, Vivancos J, Del Ser T. Poststroke dementia. Clinical features and risk factors. Stroke 2000;31:1494-1501.

25. Tatemichi TK, Paik M, Bagiella E, Desmond DW, Pirro M, Hanzawa LK. Dementia after stroke is a predictor of longterm survival. Stroke 1994;25:1915-1919.

26. Goodglass H, Kaplan E. The assessment of aphasia and related disorders. 2nd ed. Philadelphia: Lea \& Febiger, 1983.

27. American Psychiatric Association. Diagnostic and statistical manual of mental disorders. 3rd ed., revised. Washington, DC American Psychiatric Association, 1987.

28. Foulkes MA, Wolf PA, Price TR, Mohr JP, Hier DB. The Stroke Data Bank: design, methods, and baseline characteristics. Stroke 1988;19:547-554.

29. Stern Y, Andrews H, Pittman J, et al. Diagnosis of dementia in a heterogeneous population: development of a neuropsychological paradigm-based diagnosis of dementia and quantified correction for the effects of education. Arch Neurol 1992;49: 453-460.

30. Folstein MF, Folstein SE, McHugh PR. "Mini-mental state": a practical method for grading the cognitive state of patients for the clinician. J Psychiatr Res 1975;12:189-198.

31. Mahoney FI, Barthel DW. Functional evaluation: the Barthel Index. Md Med J 1965;14:61-65.

32. Williams JBW. A structured interview guide for the Hamilton Depression Rating Scale. Arch Gen Psychiatry 1988;45:742-747.

33. Blessed G, Tomlinson BE, Roth M. The association between quantitative measures of dementia and of senile change in the cerebral grey matter of elderly subjects. Br J Psychiatry 1968; 114:797-811.

34. Román GC, Tatemichi TK, Erkinjuntti T, et al. Vascular dementia: diagnostic criteria for research studies. Report of the NINDS-AIREN International Workshop. Neurology 1993;43: $250-260$.

35. Walsh JS, Welch HG, Larson EB. Survival of outpatients with Alzheimer-type dementia. Ann Intern Med 1990;113:429-434.

36. Heyman A, Peterson B, Fillenbaum G, Pieper C. The Consortium to Establish a Registry for Alzheimer's Disease (CERAD). Part XIV: demographic and clinical predictors of survival in patients with Alzheimer's disease. Neurology 1996;46:656-660.

37. Gurwitz JH, Monette J, Rochon PA, Eckler MA, Avorn J. Atrial fibrillation and stroke prevention with warfarin in the long-term care setting. Arch Intern Med 1997;157:978-984.

38. Moroney JT, Tseng CL, Paik MC, Mohr JP, Desmond DW. Treatment for the secondary prevention of stroke in older patients: the influence of dementia status. J Am Geriatr Soc 1999;47:824-829.

39. Krumholz HM, Radford MJ, Ellerbeck EF, et al. Aspirin for secondary prevention after acute myocardial infarction in the elderly: prescribed use and outcomes. Ann Intern Med 1996; 124:292-298

40. Hachinski V. Vascular dementia: a radical redefinition. Dementia 1994;5:130-132.

41. Olichney JM, Hofstetter CR, Galasko D, Thal LJ, Katzman R. Death certificate reporting of dementia and mortality in an Alzheimer's disease research center cohort. J Am Geriatr Soc 1995;43:890-893.

42. Beard CM, Kokmen E, Sigler C, Smith GE, Petterson T, O'Brien PC. Cause of death in Alzheimer's disease. Ann Epidemiol 1996;6:195-200. 
43. Morrison RS, Siu AL. Survival in end-stage dementia following acute illness. JAMA 2000;284:47-52.

44. van Dijk PTM, Dippel DWJ, Van Der Meulen JHP, Habbema JDF. Comorbidity and its effect on mortality in nursing home patients with dementia. J Nerv Ment Dis 1996;184:180-187.

45. Desmond DW, Tatemichi TK, Paik M, Stern Y. Risk factors for cerebrovascular disease as correlates of cognitive function in a stroke-free cohort. Arch Neurol 1993;50:162-166.

46. Desmond DW, Tatemichi TK, Stern Y, Sano M. Cognitive dysfunction following first stroke. Neurology 1992;42(suppl 3):426. Abstract.
47. Tatemichi TK, Paik M, Bagiella E, et al. Risk of dementia after stroke in a hospitalized cohort: results of a longitudinal study. Neurology 1994;44:1885-1891.

48. Moroney JT, Bagiella E, Desmond DW, Paik MC, Stern Y, Tatemichi TK. Risk factors for incident dementia after stroke. Role of hypoxic and ischemic disorders. Stroke 1996;27:12831289.

49. Moroney JT, Bagiella E, Tatemichi TK, Paik MC, Stern Y, Desmond DW. Dementia after stroke increases the risk of long-term stroke recurrence. Neurology 1997;48:13171325 .

\title{
Sporadic Creutzfeldt-Jakob disease and surgery
}

\section{A case-control study using community controls}

\author{
H.J.T. Ward, MFPHM; D. Everington, MSc; E.A. Croes, MD; A. Alperovitch, MD; \\ N. Delasnerie-Lauprêtre, MD; I. Zerr, MD; S. Poser, MD; and C.M. van Duijn, PhD, for the European \\ Union (EU) Collaborative Study Group of Creutzfeldt-Jakob Disease (CJD)*
}

\begin{abstract}
Background: The cause of sporadic Creutzfeldt-Jakob disease (CJD) is unknown. Previous studies found a link with a history of surgery but had methodologic problems. Objective: To help elucidate medical and associated risk factors for sporadic CJD as part of the 1993 to 1995 European Union collaborative studies of CJD. Methods: Medical and associated risk factors from 326 patients with sporadic CJD, taken from population-based studies performed between 1993 and 1995 in France, Germany, the Netherlands, and the UK, were compared with 326 community controls recruited by telephone in 2000. Results: A history of surgery was significantly associated with the risk of sporadic CJD (odds ratio [OR]: 1.8; $95 \%$ CI: 1.2 to 2.6), which was not dependent on the number of surgical procedures, and was stronger in females (OR: 2.5; 95\% CI: 1.5 to 4.0). Gynecologic (OR: 1.5; 95\% CI: 1.0 to 2.3) and "other" operations (any operation other than neurologic, eye, ear, gallbladder, gastrointestinal, and gynecologic operations, tonsillectomy, and appendectomy) (OR: 1.5; 95\% CI: 1.1 to 2.1) were associated with risk of CJD. Tonsillectomy (OR: 0.3; 95\% CI: 0.2 to 0.5 ) and appendectomy (OR: 0.6; $95 \%$ CI: 0.4 to 0.8 ) were observed less frequently in cases. An increased risk was also found with a history of ear piercing in females (OR: 1.6; 95\% CI: 1.1 to 2.5) and psychiatric visit(s) (OR: 2.6; 95\% CI: 1.5 to 4.3). Conclusions: These results support the hypothesis that cases of sporadic CJD may result from hitherto unrecognized surgical contamination events. However, because of the limits of the study design, the rarity of the disease, and the potential for bias, the results should be interpreted with caution.
\end{abstract}

NEUROLOGY 2002;59:543-548

Creutzfeldt-Jakob disease (CJD) is one of the transmissible spongiform encephalopathies. The most common form, sporadic CJD, has an unknown etiology. There are various hypotheses to explain the occurrence of sporadic CJD, ranging from normal prion protein $(\mathrm{PrP})$ spontaneously misfolding and aggregating as an abnormal form of the prion protein $\left(\mathrm{PrP}^{\mathrm{Sc}}\right)^{1}$ through to rare spontaneous somatic mutations of $\operatorname{PrP}^{1}$ and to low-level contamination events. ${ }^{2}$ With the spread of bovine spongiform encephalopa-

\section{See also page 488}

*See the Appendix for a complete listing of the members of the EU Collaborative Study Group of CJD.

From the National CJD Surveillance Unit (Dr. Ward and D. Everington), Western General Hospital, Edinburgh, UK; Department of Epidemiology and Biostatistics (Drs. van Duijn and Croes), Erasmus University Medical Centre Rotterdam, the Netherlands; U360 INSERM (Drs. Alperovitch and DelasnerieLauprêtre), Hôpital de la Salpetrière, Paris, France; and Neurologische Klinik (Drs. Zerr and Poser), Georg-August Universität, Göttingen, Germany.

Performed under the auspices of the EU Concerted Action on the Epidemiology of CJD funded through the BIOMED 2 Program (project no. BMH4-CT972216). The INSERM Unit 360 in France is supported by the Institut de la Vielle Sanitaire. The German CJD Surveillance Study Göttingen/Munich is funded by the Federal Ministry of Health (Bundesministerium für Gesundheit, GZ 325-4471-02/15). The studies in the Netherlands were supported by the Netherlands Institute for Health Sciences and the Netherlands Organization of Scientific Research. The study in the UK was funded by the Department of Health and the Scottish Home and Health Department.

Received November 2, 2001. Accepted in final form April 23, 2002.

Address correspondence and reprint requests to Dr. H.J.T. Ward, National CJD Surveillance Unit, Western General Hospital, Edinburgh, EH4 2XU, UK; e-mail: h.ward@ed.ac.uk 